\title{
Erratum to: Hydrochemistry of Fluoride in Groundwaters from the Permo-Triassic Aquifer System of Central Shaanxi Province, Northwest China
}

\author{
Yan Dou ${ }^{1,2} \cdot$ Ken Howard $^{3} \cdot$ Liwei Yang ${ }^{1}$ Dong Wang ${ }^{4} \cdot$ Li Guo $^{4}$
}

Published online: 20 December 2016

(C) Springer Science+Business Media Dordrecht 2016

\section{Erratum to: Expo Health (2016) 8:419-429 DOI 10.1007/s12403-016-0218-6}

Due to an unfortunate turn of events, the name of the first author appeared incorrectly in the original publication and should have read Yan Dou.
The correct representation of the authors' names is listed above and below and should be treated as definitive.

The online version of the original article can be found under doi: 10.1007/s12403-016-0218-6.

Yan Dou

yan.dou@utoronto.ca

1 School of Environmental Science and Engineering, Chang' an University, No. 126 Yanta Road, Xi' an 710054, People's

Republic of China

2 Key Laboratory of Subsurface Hydrology and Ecological Effects in Arid Region of the Ministry of Education, Chang'an University, No. 126 Yanta Road, Xi' an 710054, People's Republic of China

3 Groundwater Research Group, University of Toronto Scarborough, Toronto, ON M1C 1A4, Canada

4 Xi' an Center of Geological Survey, CGS, Xi' an 710054, People's Republic of China 